\title{
"Tiempos de egotismos superhombríos y otras nietzschedades": la recepción de Friedrich Nietzsche en la obra de Rubén Darío ${ }^{1}$
}

\section{"Tiempos de egotismos superhombríos y otras nietzschedades": The reception of Friedrich Nietzsche in Ruben Dario's work}

\author{
JUAN PABLO PINO-POSADA \\ ${ }^{a}$ Universidad EAFIT, Departamento de Humanidades. Medellín, Colombia. \\ Correo electrónico: jppinop@eafit.edu.co
}

El artículo describe la recepción de la obra y la figura de Friedrich Nietzsche en la producción literaria y periodística de Rubén Darío. Se constata que, después de un entusiasmo inicial y pionero - hasta donde se sabe, Rubén Darío es el primer autor hispanoamericano que escribe sobre Nietzsche-, la actitud del poeta nicaragüense respecto del filósofo alemán se hace cada vez más ambivalente y desemboca en una compleja mezcla de asimilación y rechazo crítico. Dicha coexistencia se afinca en la pertenencia dariana a las contradicciones epocales de la modernidad tardía y su proceso secularizador. Para mostrar lo anterior, el artículo expone tres focos temáticos de influencia de la filosofía nietzscheana —el nihilismo, el aristocratismo y la metafísica de artista— y a continuación perfila su recepción por parte de Rubén Darío bajo las formas del Nietzsche raro, anticristiano y romántico. La presencia conflictiva de dichas formas permite explicar tensiones estructurales de la subjetividad poética dariana y ofrecen el marco para el análisis conclusivo del célebre poema "Lo fatal".

Palabras claves: Rubén Darío (1867-1916), Friedrich Nietzsche (1844-1900), teoría de la recepción, modernismo hispanoamericano, nihilismo, modernidad.

The article describes the reception of Friedrich Nietzsche's work and character in Ruben Dario's literary and journalistic production. It can be determined that, after an initial and groundbreaking enthusiasm -as far as we know, Ruben Dario is the first Hispanic American who writes about Nietzsche-, the Nicaraguan poet's attitude about the German philosopher becomes more ambivalent and it flows into a complex mixture of assimilation and critical rejection. Such coexistence settles in its Darian belonging to the late modernity and its secularizing process. In order to show the above mentioned, the article presents three focal points of the Nietzschean philosophy -nihilism, aristocratism and the artist's metaphysics- and it then profiles Ruben Dario's reception under the

\footnotetext{
${ }^{1}$ El presente artículo está adscrito al proyecto de investigación “¿Cómo (no) vivir? Representaciones literarias de la vida buena” (cód. 913-000044) financiado por la Universidad EAFIT. El autor agradece de manera especial a Salome Loos su interlocución en la fase germinal de las presentes pesquisas.
} 
forms of the uncommon, antichristian and romantic Nietzsche. The controversial presence of such forms allows for the explanation of the structural tensions of the Darian poetic subjectivity and it offers the framework for the conclusive analysis of the celebrated poem "Lo fatal".

Key words: Ruben Dario (1867-1916), Friedrich Nietzsche (1844-1900), theory of reception, Hispanic American modernism, nihilism, modernity.

\section{INTRODUCCIÓN}

Objeto del presente artículo es la recepción en la obra de Rubén Darío (18671916) de la filosofía de Friedrich Nietzsche (1844-1900) y, particularmente, la manera en que dicha recepción da cuenta de las tensiones tardomodernas de la obra rubendariana. Con tensiones tardomodernas me refiero al conjunto de conflictos que se desencadenan a partir de la segunda mitad del siglo xIx en el seno de la subjetividad literaria de raigambre europea y que se sitúan en el contexto más amplio de la crisis de la unidad cartesiana del sujeto, crisis ocasionada por el develamiento discursivo —en las obras de Marx, Freud, Darwin y Nietzsche, entre otros - de poderes heterónomos como el capital, el inconsciente, la historia evolutiva y la gramática, respectivamente (cf. Zima 86).

Como bien lo señala toda una vertiente de los estudios literarios desde que Federico de Onís lo declarase en 1934 (p. xv), la variante hispánica de esta crisis es el modernismo hispanoamericano, variante que, a su turno, encuentra en Rubén Darío su exponente más representativo. En las páginas siguientes interesa mostrar que tres aspectos de la crisis en cuestión configuran el escenario sociocultural en el que Rubén Darío entra en contacto con la figura de Nietzsche: el avance de la secularización, el llamado al individualismo y el consuelo en el esteticismo. Tales aspectos se presentan en el filósofo alemán bajo los conceptos de nihilismo, aristocratismo y metafísica de artista y se articulan poética y poetológicamente en el autor nicaragüense bajo la conciencia de las grandes tensiones entre espiritualidad e instintividad, individualidad y pertenencia a un colectivo y autonomía artística y compromiso político, polos todos respecto de los cuales, de manera contradictoria, Rubén Darío se siente alternativamente llamado y repelido. También interesa mostrar que en dicha conciencia conflictual se afinca la ambivalencia de la recepción rubendariana de la figura de Nietzsche — su vaivén entre acogida entusiasta y rechazo crítico—, pues si bien Darío saluda o experimenta en sí las transformaciones ético-estéticas diagnosticadas y catalizadas por el autor del Así habló Zaratustra y en consecuencia es receptivo para algunas de sus ideas, fórmulas y personajes, está lejos del deseo de ruptura completa —a "martillazos"— con el propio pasado y la propia tradición.

Tras las consideraciones introductorias de esta primera parte sobre la perspectiva de análisis y la presencia en la literatura crítica de la problemática abordada, se describirán en la segunda parte los tres focos temáticos de influencia de la filosofía nietzscheana recién mencionados — "2.1 El nihilismo"; "2.2 El aristocratismo" y "3.3 La metafísica de artista”- 
para a continuación perfilar su recepción por parte de Rubén Darío bajo las formas del Nietzsche raro, del Nietzsche anticristiano y del Nietzsche romántico (apartados 3.1, 3.2 y 3.3). La presencia conflictiva de dichas formas permitirá explicar las tensiones estructurales de la subjetividad literaria en Rubén Darío y ofrecerá el marco para el análisis conclusivo del célebre poema "Lo fatal" (también en el apartado 3.3).

Como es sabido, Nietzsche fue desde muy temprano objeto de una recepción positiva por parte de artistas y escritores europeos, quienes, contrario a lo ocurrido en el ámbito de la filosofía universitaria, se acercaron sin muchas reservas y más bien con creciente entusiasmo al contenido y a las formas de obras ciertamente atípicas como Die Geburt der Tragödie (El nacimiento de la tragedia) (1872), Also sprach Zarathustra (Asi habló Zaratustra) (1883) o Ecce homo (1888). Muy atento al acontecer cultural de Europa y, en particular, de Francia, Rubén Darío entra en contacto con el nombre de Nietzsche en la década del noventa a través de las publicaciones francesas a las que tiene acceso en sus viajes por América y por la misma Europa. El testimonio textual más temprano de dicho contacto data de 1894, año en el que Darío, radicado en Argentina, publica una nota para La Nación de Buenos Aires titulada "Los raros. Filósofos «finiseculares». Nietzsche Multatuli". El documento — sobre cuya significación se hablará en detalle más abajo en el apartado 3.1- constituye en efecto la primera de una extendida serie de huellas de la compleja y sintomática recepción del filósofo alemán por parte de la figura más influyente del modernismo hispanoamericano. Las marcas textuales aparecen prácticamente a lo largo de toda la obra de adultez de Rubén Darío, esparcidas no solo en los versos de su poesía sino también en la prosa de las notas periodísticas, los artículos de crítica literaria, las crónicas de viaje y los fragmentos autobiográficos. Quien siga el encadenamiento de dichas huellas puede constatar que la evolución de la recepción está lejos de ser unívoca, que no se resuelve simplemente en una abierta aceptación ni en un férreo rechazo, sino que más bien asume la forma de una ambivalente y necesaria confrontación con una tendencia contemporánea de pensamiento que articulaba y catalizaba realidades de las que el mismo Darío participaba.

Por recepción se entiende aquí el conocimiento de que es objeto un autor por parte de otro sobre la base de un determinado "horizonte de expectativas" (Jauß 131). El horizonte de expectativas desde donde Darío divisa la figura de Nietzsche es un contexto sociocultural favorable para la inserción del filósofo en el universo espiritual del poeta en cuanto que Darío como autor-receptor es partícipe de procesos modernizadores que Nietzsche como autor-recibido diagnostica y acelera con marcada vehemencia. Por otro lado, en el caso de Darío, la modalidad específica de recepción de que se trata es, de acuerdo con la nomenclatura de Moog-Grünewald (81-82), la recepción reproductiva, esto es, aquella que se manifiesta mediante críticas, comentarios y apuntes; operación que por tanto no se queda en el silencio de la recepción pasiva - ajena por definición al testimonio escrito- pero que tampoco constituye el origen causal de una nueva obra por parte del autor receptor, como sería el caso de la recepción productiva. En este orden de ideas, no puede afirmarse que la presencia de Nietzsche en Rubén Darío sea la del influjo seminal al modo en que lo fue la presencia de Nietzsche en André Gide o, en el mismo Darío, la presencia de Victor Hugo; 
puede hablarse, mejor, de una confrontación fecunda con fines de autoesclarecimiento ético y estético que tiene lugar en virtud de la búsqueda cosmopolita del receptor.

La recepción de la obra nietzscheana en la producción de Rubén Darío ha sido objeto de interés tanto por parte de especialistas en la obra del filósofo alemán como por parte de los estudiosos darí́stas. Hasta hace poco se trataba de un tema relativamente marginal en ambas orillas investigativas, lo cual no deja de sorprender a la luz del hecho de que Rubén Darío haya sido el primer hispanoamericano en escribir sobre Nietzsche y de que, además, el gesto pionero fuese concebido inicialmente como parte del proyecto original de Los raros, valga decir, uno de los libros capitales no solo del corpus dariano sino también de todo el movimiento modernista. Recientemente, sin embargo, se han producido avances significativos en este ámbito específico de la recepción gracias a reediciones de fuentes originales y a dos artículos de Günther Schmigalle: "«Yo soy el anticristo de la América Central». Lecturas y crisis espiritual de Rubén Darío en 1913”, publicado en 2016, y "Darío, lector de Nietzsche", publicado en 2018.

En efecto, dentro de la bibliografía dariísta, cabe destacar como antecedente importante de los artículos de Schmigalle la contribución de Noel Rivas Bravo titulada "Un raro excluido de Los raros", seguimiento minucioso, aunque no carente de imprecisiones, que supera con mucho artículos académicos que vinieron posteriormente, como por ejemplo el discreto texto de Javier García Cristóbal ("Una aproximación a la influencia de Friedrich Nietzsche en la obra de Rubén Darío"). ${ }^{2}$ Representativos de los estudios circunscritos a Nietzsche son dos títulos ya clásicos: Nietzsche in der Hispania. Ein Beitrag zur hispanischen Kultur-und Geistesgeschichte (Nietzsche en el mundo hispánico. Una contribución a la historia de la cultura y de las ideas hispánicas), publicado en 1962 por Udo Rukser; y Nietzsche en España, libro publicado en 1967 por Gonzalo Sobejano y del que existe una segunda edición ligeramente ampliada de 2004.

Podría decirse que, en términos generales, la línea que dibujan estos títulos es la de una evolución en cuanto al inventario de las marcas textuales identificables en la obra dariana. Sobre la base del escrito pionero que dedica Darío a Nietzsche, Rukser considera que Darío no posee en realidad "ningún conocimiento" de Nietzsche (41). Dicho escrito es para Rukser apenas un "trabajo apurado", "débil" y de una "vergonzosa insuficiencia" (41-42). Independientemente de si semejante juicio es exagerado o no, lo que resulta problemático en el estudio de Rukser es el silencio respecto de la obra posterior y en consecuencia la generalización, bastante equivocada entonces, de la eventual ignorancia inicial de Darío (Rukser 313). Sobejano, a diferencia de Rukser, si bien califica también el escrito de "precipitado", rastrea con más celo —y éxito- la restante obra de Darío y encuentra en ella múltiples indicios de la influencia del nietzscheísmo imperante (48). Para Sobejano, esta influencia se refleja sobre todo en el "ideal apolíneo de belleza" que Rubén

\footnotetext{
${ }^{2}$ Sobre la presencia de Nietzsche en el ámbito literario hispanohablante pueden consultarse además las tesis doctorales de Pablo Drews (Recepción y crítica de la obra de Nietzsche en Uruguay 1900 1920) y Erik Ewald Hüneburg (Nietzsche und die spanische Literatur der Moderne [1898-1936]) así como el artículo de Thomas Ward titulado "Los posibles caminos de Nietzsche en el Modernismo".
} 
Darío comparte con Nietzsche y que tiene su expresión en las creencias en la superioridad del arte, en el rango de la claridad mediterránea y en lo admirable de la vitalidad humana y epocal del Renacimiento (197-200). Adicionalmente, señala Sobejano, el rasgo nietzscheano más constante en la recepción de Darío es el aristocratismo, mientras que aquel con el que se siente más incómodo es el anticristiano (200-201). En esto último concuerda Rivas Bravo, quien por otra parte atribuye a Darío — con abundantes pruebas textuales— mucho más conocimiento de Nietzsche que el concedido por los otros dos estudiosos (75) y quien además localiza la recepción dariana en el ámbito de "las luchas interiores" que tensan la personalidad artística de Darío, esto es, "el antagonismo entre la carne y el espíritu", "la vertiente dionisíaca de su alma y su cristianismo esencial" (80). Schmigalle, finalmente, precisa aún más el registro de las marcas textuales, da cuenta de la intermitencia del interés dariano en Nietzsche — no solo señala cuándo y dónde hay referencias nietzscheanas sino también cuándo y dónde debería haberlas y no las hay ("Darío, lector de Nietzsche" 136)— y, de manera particularmente útil, rastrea las fuentes de primera y segunda mano mediante las cuales Darío entró en contacto con el filósofo alemán.

El presente artículo se sitúa en el horizonte abierto por el planteamiento de Rivas Bravo en torno a los antagonismos interiores de Rubén Darío y se sirve de la claridad filológico-documental arrojada por Schmigalle. Pero, adicionalmente, se entiende como un progreso interpretativo de la obra rubendariana que toma mucho más en cuenta el texto mismo de las ideas filosóficas propagadas por Nietzsche, que identifica de manera sustantiva la conexión de ellas con el proyecto estético de Rubén Darío — conexión que no es meramente nominal sino que se funda en analogías de contexto sociocultural- y que analiza bajo esta nueva luz uno de los poemas más paradigmáticos del modernismo hispanoamericano.

\section{Tres aspectos de LA filosofía de NiETzSCHE}

\subsection{El nihilismo}

La idea de la muerte de Dios la formula Nietzsche por primera vez en el fragmento 125 de Die fröhliche Wissenschaft (La ciencia jovial), libro publicado en 1881. El fragmento, titulado "El loco" (Der tolle Mensch), es quizás uno de los textos más citados del filósofo alemán. Contiene un breve relato en el que se cuenta cómo al mediodía un loco encendió una lámpara y comenzó a gritar en el mercado que buscaba a Dios. Los lugareños, dentro de los cuales había "muchos que precisamente no creían en Dios", estallaron en carcajadas mientras se preguntaban irónicamente por el posible paradero: “¿¿Es que se ha perdido?», dijo uno. "¿Se ha extraviado como un niño?», dijo otro. "iO es que se mantiene escondido? [...] ¿'Se ha embarcado en un navío?»” (La ciencia jovial 114; KSA 3, 480)3. El loco, a su

\footnotetext{
${ }^{3}$ Para las obras de Nietzsche, cito inicialmente la edición en español y añado a continuación el tomo y la página correspondiente de la edición crítica alemana, precedida de sigla KSA (Kritische Studienausgabe).
} 
turno, responde que "Dios ha muerto" y que entre todos lo hemos matado. Tras manifestar su asombro ante dicho asesinato - "¿Cómo fuimos capaces de beber el mar? ¿Quién nos dio la esponja para borrar todo el horizonte?”-, se pregunta: “¿No es la grandeza de este hecho demasiado grande para nosotros?" (La ciencia jovial 115; KSA 3, 480). Al final, el loco constata que aún es temprano para que su voz sea escuchada y decide irrumpir en cada iglesia para cantarle a Dios un réquiem.

Del fragmento cabe destacar dos aspectos. El primer aspecto consiste en el hecho de que el loco anuncie la muerte de Dios especialmente ante los no creyentes. La muerte de Dios significa para Nietzsche que "la creencia en el Dios cristiano se ha vuelto poco creíble" (La ciencia jovial 203; KSA 3, 573). Ello afecta no solo a los creyentes sino también a los no creyentes, pues a través de esa muerte no solo las instituciones religiosas sino también los modelos vigentes de explicación del mundo y las representaciones morales comienzan a perder validez. En efecto, el Dios cristiano es para Nietzsche no solo una instancia religiosa sino sobre todo la quintaesencia del mundo suprasensible, esto es, el mundo que desde Platón y para toda la metafísica occidental funge como el único verdadero. Que este Dios haya muerto significa entonces que todo lo que en los últimos 2500 años valió como verdadero deja de ser vinculante. "¿No vamos de aquí para allá como a través de una nada infinita?”, pregunta el loco (La ciencia jovial 115; KSA 3, 480). Es decir: el orden proveedor de sentido ha desaparecido y el sistema de valores no ofrece ya ninguna orientación. La ausencia que se percibe es entonces la del sentido de la vida.

Precisamente un estado tal de pérdida de sentido es lo que Nietzsche llama nihilismo. El nihilismo designa un estado en el que "falta la meta" y la "respuesta al "ipor qué?»" y significa específicamente, como dice Nietzsche en una nota póstuma, "que los valores supremos se desvalorizan" (Fragmentos póstumos 241; KSA 12, 350, énfasis en el original). Los valores supremos - a saber, "lo existente, lo incondicionado, lo bueno, lo verdadero, lo perfecto" (Crepuisculo de los idolos 54; KSA 6, 76) -, de los cuales el hombre extrae un fundamento y una meta, se desvalorizan, se vuelven poco creíbles. Esto quiere decir que estos valores aparecen como ficción, invento, mentira.

De este estado de nihilismo se desprende una exigencia: si los viejos valores ya no valen más, ¿qué se ha de hacer entonces? Es decir: ¿a través de cuáles valores se reemplazan los viejos? Sobre todo: ¿se encuentra el hombre actual en condiciones de crear dichos valores? Por eso pregunta el loco - y este es el segundo aspecto por resaltar del fragmento-: jes la dimensión de ese hecho demasiado grande para nosotros?

Nietzsche distingue tres reacciones diferentes a dicho nihilismo, es decir, distingue tres tipos de hombre. En primer lugar, el pesimista. La falta de sentido de la vida ofrece al pesimista una razón para negar la vida y suspender la voluntad. Según la etimología (pessimis, lo más malo), para él este mundo es el peor de todos los posibles. La existencia en él no encuentra ninguna justificación. En segundo lugar, el último hombre. El último hombre es aquel que se encuentra satisfecho con el nihilismo. Ha encontrado en él una zona de confort y afirma incluso haber inventado la felicidad. La desvalorización de los valores supremos no representa para él ninguna dificultad; es incluso mejor que los valores 
sean pequeños, piensa él, pues todo es pequeño. Su signo es convertirlo todo en pequeño. Él no puede representarse nada mejor y no tiene ninguna sensibilidad para ideales, en general para grandeza. Por eso pregunta haciendo alarde de ignorancia: "¿qué es amor? ¿Qué es creación? ¿Qué es anhelo? ¿Qué es estrella?” (Asi hablaba Zaratustra 41; KSA 7, 19). Nietzsche imagina esta incapacidad para la grandeza bajo la figura de la "pulga": "La tierra se ha vuelto pequeña - dice Zaratustra - y sobre ella salta el último hombre" (Asi hablaba Zaratustra 41; KSA 7, 19). Finalmente, en tercer lugar, el emigrante. Emigrantes son aquellos que ven en el nihilismo el tránsito que posibilitará un nuevo mundo y un nuevo hombre. Ellos se comprenden a sí mismos como un lazo o un puente entre los viejos valores y los nuevos, esto es, los valores que están por crearse. Nietzsche mismo — quien, según su propia opinión, pertenece a estos hombres - describe este estado intermedio como algo que trae consigo cierta alegría, cierto envalentonamiento, cierta expectativa. Para ello usa él la imagen de la aurora, imagen que por demás da título al libro publicado en 1881 "sobre los prejuicios morales" y que en la invitación a la migración asume la forma específica del sol naciente en el mar, en cuya costa se disponen a zarpar marineros alegres:

finalmente el horizonte se nos aparece libre de nuevo, aun cuando no esté despejado; finalmente podrán zarpar de nuevo nuestros barcos, zarpar hacia cualquier peligro, de nuevo se permite cualquier riesgo de los que conocen; el mar, nuestro mar, yace abierto allí de nuevo, tal vez nunca hubo antes un "mar tan abierto". (La ciencia jovial 204; KSA 3, 574)

En este horizonte libre, en este mar abierto han de avistarse en algún momento nuevos valores, sobre todo ha de venir un nuevo hombre al mundo. Nietzsche llama a este nuevo hombre el superhombre.

\subsection{El aristocratismo}

Ahora bien, ¿por qué un nuevo hombre? El diagnóstico nietzscheano del hombre moderno es desolador. El resultado de la moral cristiana y de las tendencias igualitaristas modernas, dice él, es un hombre que no solo promueve una conducta negadora respecto de la vida terrenal, sino también — muy en el espíritu del ya mencionado último hombrealguien que minimiza la posibilidad de surgimiento de un tipo de hombre excepcional. Frente al genio, el espíritu libre o, en un nivel mayor, el superhombre, se contrapone la nivelación y mediocridad de la masa: "Pues así están las cosas: el empequeñecimiento y la nivelación del hombre europeo encierran nuestro máximo peligro, ya que esa visión cansa [...]. ¿[Q]ué es hoy el nihilismo si no es eso?... Estamos cansados de el hombre..." (La genealogía de la moral 58; KSA 5, 278, énfasis en el original).

Este aspecto aristocrático y antidemocrático de la filosofía nietzscheana no era escaso en las últimas décadas del siglo XIX y gozaba de hecho de gran beneplácito en la recepción temprana que se hizo de ella. Uno de los primeros estudios detallados sobre 
Nietzsche, publicado en 1890 por Georg Brandes (1842-1927), se llama justamente Friedrich Nietzsche. Eine Abhandlung über aristokratischen Radikalismus (Friedrich Nietzsche. Un tratado sobre el radicalismo aristocrático). A propósito del llamativo título se expresa Nietzsche en una carta de 1887 en los siguientes términos: "Es, dicho sea con permiso, la palabra más inteligente que he leído hasta ahora sobre mî" (Correspondencia 79; cit. también en Brandes 25). Radicalismo aristocrático quiere decir, según se infiere del trabajo de Brandes, una filosofía moral de corte crítico ante la civilización, que considera educación y cultura como la posibilidad de la formación de hombres excepcionales. Para el mismo Brandes, dicho radicalismo se sintetiza en la siguiente cita de Nietzsche, tomada de "Schopenhauer als Erzieher" ("Schopenhauer como educador"): "la humanidad ha de trabajar incansablemente en la procreación de grandes individuos aislados. Esta y no otra es su tarea" (780; KsA 1, 383-384; cit. también en Brandes 41-42). Nietzsche entenderá paradigmáticamente este individuo aislado como el artista genio.

\subsection{La metafisica de artista}

El culto elitista de Nietzsche respecto del genio se basa entre otras cosas en el papel del arte en su filosofía temprana. Ya al comienzo de su primer libro, Die Geburt der Tragödie (El nacimiento de la tragedia), dice el joven Nietzsche que está convencido de que "el arte es la tarea suprema y la auténtica actividad metafísica de esta vida" (40; KSA 1, 24). A lo que él se refiere llega a ser claro algunas páginas más adelante. Para Nietzsche, el lírico de la Antigüedad griega crea su obra en cuanto que se transforma en una suerte de médium en un estado de trance a causa de la posesión de un dios creador, de tal modo que su obra no resulta como producto de una voluntad individual sino de una instancia divina. Nietzsche entonces añade lo siguiente:

Pues tiene que quedar claro sobre todo, para humillación y exaltación nuestras, que la comedia entera del arte no es representada en modo alguno para nosotros, con la finalidad tal vez de mejorarnos y formarnos, más aún, que tampoco somos nosotros los auténticos creadores de ese mundo de arte: lo que sí nos es lícito suponer de nosotros mismos es que para el verdadero creador de ese mundo somos imágenes y proyecciones artísticas, y que nuestra suprema dignidad la tenemos en significar obras de arte - pues sólo como fenómeno estético están eternamente justificados la existencia y el mundo. (El nacimiento de la tragedia 68-69; KSA 1, 47)

No el hombre de a pie, sino solo el genio, explica Nietzsche a continuación, está en condiciones de ver el mundo y a sí mismo como creación estética de un artista originario, en cuanto que se fusiona, "en el acto de la procreación artística", con el mencionado "verdadero creador". El individuo normal no es consciente de ello. La figura en una pintura, por ejemplo, no tiene conciencia de su existencia como obra de arte. De manera semejante nos falta a nosotros la conciencia de lo que somos nosotros y de lo que el mundo es. 
Con esta tesis metafísica espera Nietzsche esclarecer el auténtico núcleo de la tragedia ática y del mito trágico, pues el artista originario, esto es, el Dios tras todo acontecer, es sobre todo Dionisos, un Dios que experimenta eterno placer en la creación y en la destrucción, que por eso mismo experimenta lo feo, lo disarmónico, lo trágico, como un momento de su goce divino.

Esta interpretación estética del mundo, en la que se perciben inconfundibles huellas del topos romántico de la religión del arte, será criticada más tarde por el mismo Nietzsche en el prólogo que antepone a una nueva edición de El nacimiento de la tragedia. La llamará "metafísica de artista" y la tildará de "arbitraria, ociosa, fantasmagórica" (32; KSA $1,17)$. Pero le reconocerá que en el fondo tuvo algo positivo, a saber, que el Dios metafísico era ante todo un dios estético y no moral, es decir, un dios para el que el mundo era la gozosa aparición de sí mismo. En todo caso, independientemente de la posterior autocrítica nietzscheana, la metafísica de artista significó una revaloración del arte en todas sus formas, lo cual encontró una caja de resonancia en Darío y en el culto modernista al arte.

\section{La Recepción de Rubén Darío}

\subsection{Recepción positiva: Nietzsche como "raro"}

Rubén Darío es, según se sabe hasta ahora, el primer hispanoamericano que escribe un artículo sobre Nietzsche (Rukser 41). Se trata de una nota para el periódico La Nación de Buenos Aires que lleva el título "Los raros. Filósofos «finiseculares». Nietzsche - Multatuli" y que apareció el 2 de abril de 1894. En 2016 la revista argentina Zaga lo reprodujo completo, como no había ocurrido a lo largo de más de un siglo.

¿Qué había leído Darío de Nietzsche en 1894? A juzgar por la nota, puede decirse que nada. Darío apenas conocía una fuente secundaria. La parte dedicada a Nietzsche consiste sobre todo en reformulaciones y extractos de dos contribuciones de Henri Albert (1869-1921) en el Mercure de France del mismo año 1884, aparecidas en los números de enero y febrero, como bien lo documenta Schmigalle ("Darío, lector de Nietzsche” 127 ss.). El germanista francés Henri Albert fue uno de los primeros traductores de Nietzsche a la lengua francesa y uno de los más asiduos divulgadores, con comentarios críticos y notas informativas, de autores alemanes en Francia. Las contribuciones de Albert que tiene ante sus ojos Darío son el artículo "Nietzsche et Georges Brandes", publicado en la edición de enero de 1894 del Mercure de France (vol. x, núm. 49), y un breve apartado de la sección "Journaux et Revues", correspondiente a la edición de febrero (vol. x, núm. 50), donde Albert se hace eco de los planes editoriales de Elisabeth Förster-Nietzsche anunciados en una revista alemana. ${ }^{4}$

\footnotetext{
${ }^{4}$ Valga anotar que toda la recepción temprana de Nietzsche en Francia se puede seguir con detalle en la página de internet https://www.nietzsche-en-france.fr/, donde las contribuciones se encuentran ordenadas por fecha y autor. Particularmente útil es el hecho de que la página se encuentre vinculada con el portal Gallica de la
} 
En su nota de La Nación, aclara Darío que los párrafos en los que se ocupa de Nietzsche son "sencillamente informativos" y no pretenden ser un "análisis crítico" ("Los raros. Filósofos "finiseculares»" 269). Darío habla en particular sobre la relación entre Georg Brandes y Nietzsche y cita algunas frases de las cartas de este último enviadas al crítico literario danés. Como recomendación para quienes quieren informarse más sobre el "artista-filósofo" (267), Darío remite, al final, a las traducciones francesas, los estudios de Henri Albert y sobre todo a la obra de Georg Brandes titulada Menschen und Werke (1893). Cuando se lee la nota de Darío después de haber hojeado las contribuciones de Henri Albert resulta bastante claro que el nicaragüense en estricto sentido no publica contenido original sino que refunde las fuentes francesas. Hoy lo llamaríamos, quizás, plagio. Se equivoca por tanto Noel Rivas Bravo cuando dice que, en la nota en cuestión, Darío "da muestra de poseer un conocimiento de la vida y obra de Nietzsche nada desdeńable" (71) y tiende a lo correcto Udo Rukser cuando habla por el contrario de "vergonzosa insuficiencia" (42). En todo caso, Darío mismo no volvió a publicar la nota, tampoco en su libro Los raros, dado a la imprenta dos años después y compuesto por artículos de periódico de la serie homónima a la que originalmente pertenecía el título sobre Nietzsche y Multatuli.

De la nota de Darío resulta interesante para las presentes reflexiones sobre todo el relieve a los rasgos elitistas de Nietzsche: "lo que es innegable es que era un alma de elección, un solitario, un estilista, un raro" ("Los raros. Filósofos "finiseculares»" 267, énfasis en el original). Es más que probable que Darío se apoyase para dicha declaración en una carta de Nietzsche a Brandes, citada por Albert ("Nietzsche et Georges Brandes" 71), en la que el remitente habla de su reducido público lector. En español el pasaje dice así: "Estimado seńor: Unos pocos lectores que uno respete en sí mismo o, de lo contrario, ninguno, — eso forma parte, de hecho, de mis deseos" (Correspondencia 78). Al respecto Darío añade lo siguiente:

La opinión que Nietzsche tenía de la aristocracia de sus lectores y apreciadores, nos da la medida de su elevación intelectual y de su nobleza estética. Él no quería los favores del gran público, la vocinglería de ciertas famas, la para ciertos artistas desdorosa democracia de la gloria. (“Los raros. Filósofos «finiseculares»" 268)

Conviene anotar que, si bien en su obra posterior, de prosa y de poesía, Darío se va a referir múltiples veces a la figura y a la filosofía de Nietzsche, nunca se expresará de modo tan positivo como lo hace en esta nota, quizás con solo una excepción. Se trata de una crónica lírica de viaje con ocasión de la excursión en barco entre Colonia y Maguncia, periplo que Darío emprendió en la primavera de 1904. El diario de viaje se llama "Por el

Bibliothèque Nationale de France (https://gallica.bnf.fr/), en el que, como es sabido, gran cantidad de revistas y periódicos se encuentran escaneados y disponibles en línea. Para una investigación de las transferencias e influencias trasatlánticas durante el modernismo, no solo en relación con Nietzsche, constituye una herramienta de primer orden. Allí por ejemplo se pueden consultar Le Figaro, Revue de Deux Mondes, Revue Bleu, todas fuentes de las que se sirvieron los modernistas. 
Rhin” y está incluido en Tierras solares, obra publicada originalmente el mismo año. En tono exaltado, Darío se declara fascinado por el paisaje, cuya bruma y cuyos castillos le evocan un mundo de leyendas y cuentos de hadas. En conexión con ello y muy en la línea de una experiencia romántica de la naturaleza, Darío relata en las líneas finales del texto el surgimiento de la "poesía sagrada" tan pronto como él se fija con más detenimiento a su entorno:

Y yo también, peregrino de arte, de americanas tierras, hecho al sol y al canto de la vida latina, he puesto el oído atento a esas palabras de las aves y de las barcas germánicas, y de esa bruma he visto surgir la eterna gracia de las almas aladas, la virtud de la sagrada poesía, a la cual no vencerán ni los odios humanos, ni las sequedades de los intereses modernos, ni la mediocridad de las chatas cabezas de los regeneradores igualitarios. Pues la soberanía del espíritu se basa en lo que está más allá del bien y del mal, más allá de nuestro planeta mismo y de nuestros conceptos de verdad y de mentira: en lo infinito, en lo absoluto. (Tierras solares 184-185)

Darío no solo tiene en mente a Nietzsche en la inconfundible referencia al topos antimoral de la superación del bien y del mal, sino también en la crítica al igualitarismo. Tanto en el tiempo de Buenos Aires como diez años después en Maguncia, el nicaragüense se siente atraído por el aristocratismo nietzscheano. Esto se corresponde con el énfasis modernista en la individualidad que subyace al proyecto editorial de Los raros y a la concepción de Darío del arte moderno en términos de "desenvolvimiento y manifestación de la personalidad" bajo la divisa "Sé tú mismo" ("Los colores del estandarte" 123), concepción que, por otra parte, coincide con una ávida exploración de referentes culturales y una apertura cosmopolita y renovadora a las transferencias de saber literario.

\subsection{Recepción negativa: Nietzsche como "Anticristo"}

El pasaje de Tierras solares se trata, como se dijo, de una excepción, pues a partir de 1894, el año de publicación de la nota sobre Nietzsche y Multatuli, se tornan más distantes las referencias al filósofo alemán. Un lector de Darío bien podría sentirse tentado a formular la tesis de que cuanto más lee el poeta a Nietzsche, más se distancia de él. Pero, a la luz de una declaración tardía según la cual Rubén Darío dijo "yo soy el Anticristo de la América Central" (cf. el análisis en el artículo homónimo de Schmigalle), una tesis de más largo alcance sería la de que, más bien, Rubén Darío terminó incorporando a su autocomprensión la figura de Nietzsche en cuanto que articulación tipológica de una tendencia ético-estética que él experimenta dentro de sí y con la que no siempre están de acuerdo sus otras tendencias. Desarrollemos esto a partir de algunos pasajes textuales.

Nietzsche aparece en los textos del poeta nicaragüense en la mayoría de ocasiones en su aspecto anticristiano, esto es, como la tendencia opuesta a la conducción de la vida de acuerdo con el cristianismo y con la interpretación del mundo que a él subyace. Darío, 
quien se entiende como cristiano y específicamente católico, sitúa las ideas de Nietzsche siempre en el polo contrario de sus propios principios morales y religiosos. Por ejemplo, en el artículo "La «Espańa negra»" del libro España contemporánea (1901), donde Darío se expresa de manera positiva, más allá de los impedimentos modernos, sobre la posibilidad de una renovación y vivificación de la Iglesia en la Península, se encuentra el siguiente pasaje:

El Anticristo nació en este siglo en Alemania [...], creó el tipo de soberbia humana, o superhumana, aplastando la caridad de Jesús; [...] desató o quiso desatar los instintos, los sexos y las voluntades; consiguió un ejército de inteligencias, y se cumplió por él más de una profecía. Pero el Anticristo alemán está en el manicomio, y el Galileo ha vencido esta vez. (España contemporánea 131-132)

Ahora bien, independientemente de la referencia celebratoria al triunfo de Jesús, el mismo Darío está lejos de desconocer la desatadura de los instintos que a sus ojos ocasionó Nietzsche y por el contrario conoce de primera mano la fuerza de los impulsos sexuales. Es proverbial el natural erótico de Darío, articulado en su poesía y en su prosa con motivos y figuras del paganismo y descrito por él mismo como "tempestuoso instinto pagano" (Antología 34). El recurso es más que una conocida fórmula de encubrimiento: el uso de retórica religiosa para referirse a realidades profanas es un típico síntoma de secularización —nihilismo, en el vocabulario de Nietzsche-, que en la literatura de las Españas, dice Rafael Gutiérrez Girardot, "se realizó de preferencia en el campo erótico" ("El modernismo incógnito" 93).

Que Darío experimentó con cierta intensidad el conflicto entre fuerzas profanas y aspiraciones religiosas y que lo simbolizó en la polaridad entre Cristo y el Nietzsche del Anticristo se muestra, con ribetes didácticos incluso, en el poema "Caminos", del año 1913. El poema comienza con los siguientes versos: "¿Qué vereda se indica, / cuál es la vía santa, / cuando Jesús predica / o cuando Nietzsche canta?” (461). Los dos caminos son el de una vida consagrada a la bondad y el de una vida dominada por la voluntad de poder. En el resto de estrofas, el hablante lírico procede a modular este dilema mediante varias oposiciones: querer y obrar, voluntad y honestidad, Francisco Pizarro y Francisco de Asís, conquistar continentes o conquistar el cielo, para cerrar así: "Santidad y heroísmo / tienen el propio vuelo / con el genio que vuela entre los dos: los Santos y los Héroes / tienen el propio cielo, / y todos ellos buscan la dirección de Dios" (462). El hablante, pues, dice que el genio "vuela entre los dos", entre Cristo y Nietzsche, Pizarro y Asís, el santo y el héroe.

En su conflictividad, este vuelo, para seguir con la metáfora, tiene que atravesar más de una turbulencia. Por ejemplo, se da el caso de que el Darío que escribe en prosa sienta el impulso de aminorar retrospectivamente la nota osada y herética que se le deslizó al Darío poeta. Cabe recordar a este respecto el poema "Anagke", de $A z u l$, en el que una paloma canta incasablemente su propia felicidad y su reconciliación con el mundo a lo largo de más de sesenta versos, justo antes de que al final —en un giro humorístico nada ajeno al significativo problema teológico de la teodicea - "un gavilán infame" la cace y la engulla y 
ponga con ello a meditar a Dios sobre los desajustes de su creación. Resulta que Juan Valera, en la célebre "Carta a D. Rubén Darío", habla a propósito de este poema en términos de blasfemia y "burla de Dios" (xxi), lo cual ocasiona una retractación ańos después por parte de Darío mismo en Historia de mis libros: "Anagke es una poesía aislada y que no se compadece con mi fondo cristiano" (Antología 18).

Concediendo que el poema sea en efecto aislado, lo que en cualquier caso no resulta episódico es la tensión interna que tiene lugar en la subjetividad literaria rubendariana. Dado que Nietzsche precisamente representa y cataliza de manera programática el cuestionamiento del cristianismo, articula una situación epocal de la que Darío — contra su propia voluntad - no se puede sencillamente marginar, pues el proceso secularizador era ya una realidad individual y social. El autor de Asi habló Zaratustra, saludado por sus encomios de la individualidad fuerte, simboliza al mismo tiempo para el poeta de Cantos de vida y esperanza aquella tendencia propia con la que él mismo se encuentra en conflicto. Para Darío, Nietzsche es algo así como el invitado no deseado en la propia casa, quien no solo no anuncia ninguna despedida sino que además reclama derechos de habitación. ¿A qué acuerdo se llega con un invitado semejante? En otras palabras, ¿cómo se reconcilia consigo misma la subjetividad literaria rubendariana?

\subsection{El poema "Lo fatal": Dario y su metafísica de artista}

En las estrofas siguientes se puede contemplar de modo inmejorable la elaboración lírica rubendariana de las tensiones tardomodernas así como de su específica resolución hispanomodernista. Se trata de los muy citados versos de "Lo fatal", el poema final de Cantos de vida y esperanza (1905). El historiador de la literatura peruano José Miguel Oviedo describe el poema como "el más grave resumen de todo el drama que vivió Darío y, quizá, el mayor monumento de nuestra poesía modernista” (308). ${ }^{5}$

"Lo fatal"

\section{A René Pérez}

Dichoso el árbol que es apenas sensitivo, y más la piedra dura porque esa ya no siente, pues no hay dolor más grande que el dolor de ser vivo, ni mayor pesadumbre que la vida consciente.

Ser, y no saber nada, y ser sin rumbo cierto, y el temor de haber sido y un futuro terror...

\footnotetext{
${ }^{5}$ En La originalidad de Rubén Dario, Enrique Anderson Imbert también resalta la importancia del poema (141147).
} 
y el espanto seguro de estar mańana muerto,

y sufrir por la vida y por la sombra y por

que no conocemos y apenas sospechamos,

y la carne que tienta con sus frescos racimos,

y la tumba que aguarda con sus fúnebres ramos,

¡Y no saber adónde vamos,

ni de dónde venimos!...

El poema tematiza la vida humana como experiencia signada por el dolor y el desconocimiento. Se sirve del motivo del valle de lágrimas, aunque al mismo tiempo suprime de manera consciente la referencia complementaria a la posibilidad de una trascendencia religiosa en el paraíso. Darío mismo dice que, en el poema, "contra mi arraigada religiosidad y a pesar mío, se levanta como una sombra temerosa un fantasma de desolación y de duda" (Antología 42). A diferencia del árbol, que solo puede sentir poco, y sobre todo en contraposición a la piedra, que no siente nada, la posesión de conciencia del hombre no representa ningún privilegio deseable, sino la "mayor pesadumbre" (v. 4). La razón de ello es el miedo que todo lo rodea, que no solo se refiere al futuro de la muerte segura y a lo que sigue, sino también a lo que ya transcurrió. Pasado y futuro están marcados por el miedo abarcador, pues ambas dimensiones pertenecen a aquello que configura lo más terrible para Darío, esto es, lo desconocido.

Llamativa resulta también la referencia a las tentaciones de la carne (v. 10). Constitutivo del fatum vida es también la fuerza de los instintos naturales. En el ya citado Historia de mis libros habla Darío de "el poder dominante e invencible de los sentidos" (Antologia 34).

En el presente artículo interesa en especial hacer una referencia a un pequeño, si bien significativo, detalle en el poema, a saber, a la partición versal al final de la última estrofa (vv. 12-13). Hasta el último momento el poema sigue el modelo de una composición de tres cuartetas, armónicamente estructuradas en rima cruzada. En condiciones normales, la última estrofa debería lucir así:

que no conocemos y apenas sospechamos, y la carne que tienta con sus frescos racimos, y la tumba que aguarda con sus fúnebres ramos, ¡Y no saber adónde vamos, ni de dónde venimos!...

Darío rompe sin embargo el isomorfismo y desplaza la segunda mitad del verso, el segundo hemistiquio, hacia abajo:

¡Y no saber adónde vamos, ni de dónde venimos!... 
Es la única vez que Darío recurre a semejante estrategia estilística, esto es, a la inesperada partición versal en medio de una estrofa métricamente clásica. Ni posteriores ni anteriores poemas escenifican una ruptura así. Uno podría incluso decir que esta ruptura se torna especialmente visible en un poema que de manera estratégica construye continuidad a través del polisíndeton, esto es, la repetición de conjunciones (la partícula "y" aparece 13 veces).

Si se toman en consideración los siguientes tres aspectos: el tema sombrío del poema, su posición estratégica al final del poemario y, tercero, la posición dentro de la totalidad de la obra lírica de Darío (Cantos de vida y esperanza es para el centroamericano el comienzo de su descenso y al mismo tiempo la cumbre y punto de giro de su vida artística), resulta prácticamente obligatorio asignarle un gran peso simbólico al sencillo recurso formal.

El referente inmediato de ambos versos es la incertidumbre del hablante, miembro del género humano, en torno a su destino y a su procedencia. La pausa versal, en virtud de la "postergación perceptiva" que ocasiona — para decirlo con Iuri Tiniánov (99)—, independiza ambas prolongaciones, el futuro y el pasado, de tal suerte que el lector capta con más autonomía cada uno de los dos momentos y, consecuentemente, percibe el punto de discontinuidad que los separa. Puede decirse que la vida humana se representa en el momento crítico del poema no como una línea continua entre lo que la precede y lo que la sucede, sino como una tensión, una desgarradura, lo cual no riñe con el hecho de que las tres estrofas sean en último término un lamento. Propongo dar un paso interpretativo más y entender la partición versal final como una concentrada iconización de los conflictos existenciales de Darío. Estos conflictos son los típicos de la subjetividad tardomoderna en cuanto ruptura: ruptura secular respecto de un orden trascendente, ruptura individualista respecto de nostalgias e ideales comunitarios y ruptura de la propia coherencia interna sin ignorar, además, la ruptura con la tradición literaria, definitoria de la poesía moderna (cf. Friedrich 12) - En la incomodidad frente al anticristianismo, en el gusto por el aristocratismo, en la conciencia conflictual de las propias tendencias contradictorias, la recepción rubendariana de Nietzsche da cuenta justamente de estas rupturas.

Cabría además preguntarse si no suenan bastante exactos los versos en cuestión — "Y no saber adónde vamos, / ni de dónde venimos"—, cuando se los lee como expresión de un latinoamericano y su experiencia de la modernidad. En la atmósfera finisecular de Rubén Darío, un latinoamericano era probablemente alguien a quien el propio pasado colonial ofrecía pocas posibilidades de identificación, del mismo modo que, con relación al futuro, era alguien para quien el movimiento de la historia no podría ser plausible o suficientemente determinado ni por la religión heredada ni, como quizás podría suponerse, por la creencia optimista en un progreso continental.

Sea como fuere, las posibilidades semánticas de la estratégica disposición verbal no terminan con ello, pues es posible apreciar otro elemento: a pesar de la ruptura intencional en la construcción regular de la estrofa, al final no se produce ninguna disonancia completa. Darío estructura la partición versal de tal modo que los nuevos finales de verso se integran sin ninguna estridencia en el sistema de rima del poema. Es decir, frente a la rima $e-f-e-f$ 
de la hipotética estrofa sin partición atípica, la rima e-f-e-f-f de la estrofa que nos legó Darío no constituye ni de lejos un sabotaje rítmico. Este detalle permanece ignorado en el análisis estructural que del poema acomete Carlos Reis, quien por otra parte ofrece una interpretación sugestiva de dicha partición versal y de la iconicidad a que da lugar. Reis no las lee en términos de fractura, sino de progresivo adelgazamiento, pues, según hace notar, los últimos tres versos tienen respectivamente 14, 8 y 6 sílabas. El filólogo portugués dice que esta reducción métrica sugiere el "desvanecimiento de una entidad que, no obstante, lucha por el prolongamiento de la existencia" (143). Se trata de una lectura perspicaz, pero que solo atiende a la progresión y no considera el movimiento regresivo que ocasiona la rima entre v. 13 y v. 10.

Darío, como decíamos, marca entonces la ruptura para inmediatamente después superarla de manera parcial en una nueva consonancia. Esta peculiaridad al micronivel fonético se deja también interpretar, como en el caso de la estructura del verso, en términos de una expresión concentrada de principios estéticos y existenciales. A pesar del miedo ante lo desconocido, a pesar del conflicto con los instintos poderosos, el hablante del poema articula de nuevo una armonía, a saber, a través de correspondencias fonéticas, lo cual refleja la confianza hispano-modernista en la "capacidad de resistencia del lenguaje" (Siebenmann 254). Se trata de una música verbal que se encuentra, como Darío mismo enfatiza, en consonancia con una música ideal. La fuente de la música ideal se encuentra en un mundo ideal, esto es, el eterno, absoluto. Una cita de "Dilucidaciones", el iluminador texto antepuesto a Canto errante, lo dice de la siguiente manera: "He meditado ante el problema de la existencia y he procurado ir hacia la más alta idealidad" ("Yo soy aquel..." 602).

El acceso a esta "más alta idealidad" es el arte: "Es el Arte el que vence el espacio y el tiempo", dice Darío ("Yo soy aquel..." 602). Este acceso no está, por supuesto, siempre garantizado, pero existe la promesa una participación posible en él. En la lengua simbólica de Darío esto significa: la voz de la naturaleza le habla sin duda al poeta, pero lo hace con enigmas. En ello yace el aspecto romántico de la lírica modernista de Darío: conciencia de una ruptura, al mismo tiempo en la esperanza de que se la pueda superar en una nueva trascendencia. A esta trascendencia Nietzsche la llamó "metafísica de artista". Si la partición versal simboliza el conflicto de Darío en tanto que individuo (eros y miedo vs. el propio cristianismo) y en tanto que latinoamericano (entre pasado colonial y futuro incierto), la consonancia vuelta a restituir simboliza la esperanza romántica de una superación de los conflictos mediante el arte.

\section{Consideración FinaL}

En uno de los capítulos de Los raros, Darío se refiere a "estos tiempos de egotismos superhombríos y otras nietzschedades" (417) como tiempos poco propicios para la difusión de la filosofía "amplia y generosa" con que Camille Mauclair estudia los temas de su libro L'Art en silence. Más allá del tono desdeñoso de la fórmula, Darío mismo reconoce con ella 
y en general con su recepción de la obra de Nietzsche la relevancia del filósofo alemán para el diagnóstico de la convulsa época en torno al fin de siècle.

En concreto, el culto al arte de Rubén Darío ostenta similitudes con la metafísica de artista del joven Nietzsche en cuanto que en ambos autores el mundo más verdadero está determinado estéticamente. La participación en ese suprasensible "más allá" otorga consuelo y redención y ofrece así una suerte de justificación del mundo. Hay que decir que la variante del joven Nietzsche es de entrada una modalidad dionisíaca que se quiere antimoral, mientras que la variante rubendariana y de otros modernistas procura permanecer en cambio dentro de un sistema religioso y moral determinado.

Ahora bien, para Darío mismo resulta inevitable no percibir, no padecer, los signos secularizadores de su tiempo. La respuesta de Darío es el culto al arte y al artista, no tanto en la línea del "egotismo superhombrío" — de la glorificación heroica del yo- cuanto en la de la localización de puertos menos inciertos, menos sujetos al arbitrio de "lo que no conocemos" y sí en cambio accesibles a la maestría del artista.

Hay que decir también que Nietzsche criticará después fuertemente su idealismo y romanticismo de juventud y profundizará aún más su filosofía del nihilismo. La metafísica de artista no soportará la crítica tardía a la metafísica (metafísica entendida como negación de la vida y el mundo sensible) y, por el contrario, lo dionisiaco, es decir, lo trágico se convertirá en una postura de radical afirmación de la vida: "un decir sí sin reservas aun al sufrimiento, aun a la culpa misma, aun a todo lo problemático y extraño de la existencia” (Ecce Homo 77; KSA 6, 311).

Darío, claro, no acompaña a Nietzsche en la radicalidad de su crítica. El cometido modernista no es tanto poner en cuestión toda la cultura europea cuanto apropiarse de ella y hacerla operativa para las búsquedas culturales y políticas del continente americano. Por ello, la fuerza de la obra de Darío en el contexto de su recepción de Nietzsche no va nunca en la figuración de una utopía o en la fijación de una meta sobrehumana cuanto en la articulación declaradamente artística de los conflictos existenciales a que conduce la búsqueda cosmopolita de conciencia epocal.

\section{OBRAS CiTADAS}

Albert, Henri. enero de 1894. "Nietzsche et Georges Brandes". Mercure de France 10.49: 70-76. Web. 15 de noviembre de 2019. <https://gallica.bnf.fr/ark:/12148/ bpt6k105104c?rk=64378;0> . febrero de 1894. "Journaux et Revues" [apartado: "Dans Magazin für Litteratur...”. Mercure de France 10.50: 188. Web. 15 de noviembre de 1019. <https:// gallica.bnf.fr/ark:/12148/bpt6k105104c?rk=64378;0>

Anderson Imbert, Enrique. 1967. La originalidad de Rubén Dario. Buenos Aires: Centro Editor de América Latina.

Brandes, Georg. Nietzsche. 2004. Introducción de Klaus Bohnen. Berlín: Berenberg. 
Darío, Rubén. 2018. «Yo soy aquel que ayer no más decía»: libros poéticos completos. Editado por Rafael de la Fuente Ballesteros y Francisco Estévez. Madrid: Fondo de Cultura de Económica.

. 2018. "Anagke". "Yo soy aquel que ayer no más decía»: libros poéticos completos. Editado por Rafael de la Fuente Ballesteros y Francisco Estévez. Madrid: Fondo de Cultura de Económica, 378-381.

. 2018. "Lo fatal". «Yo soy aquel que ayer no más decia»: libros poéticos completos. Editado por Rafael de la Fuente Ballesteros y Francisco Estévez. Madrid: Fondo de Cultura de Económica, 593-594.

. 2016. "Los raros. Filósofos «finiseculares». Nietzsche - Multatuli". Zama, vol. 8, n. ${ }^{\circ}$ Extraordinario: Rubén Darío, 267-70. Web. 15 de noviembre de 2019. . 2016. Tierras solares. Edición de Noel Rivas Bravo. Sevilla: Renacimiento. . 2015. Los raros. Edición crítica, introducción y notas por Günther Schmigalle. Berlín: edition tranvía / Verlag Walter Frey. . 2013. España contemporánea. Edición de Noel Rivas Bravo. Sevilla: Renacimiento. $<$ http://revistascientificas.filo.uba.ar/index.php/zama/article/view/3430/3155> . 1977. "Caminos". Poesía. Prólogo de Ángel Rama, edición de Ernesto Mejía Sánchez y cronología de Julio Valle-Castillo. Caracas: Biblioteca Ayacucho, 461-462. . 1938. Escritos inéditos de Rubén Dario. Edición de E. K. Mapes. New York: Instituto de las Espańas en los Estados Unidos.

. 1938. "Los colores del estandarte". Escritos inéditos de Rubén Dario. Edición de E. K. Mapes. New York: Instituto de las Españas en los Estados Unidos, 120-123. . 1916. Antología. Poesías de Rubén Darío. Precedida de la historia de mis libros. Madrid: Pueyo.

Drews López, Pablo. 2013. Recepción y crítica de la obra de Nietzsche en Uruguay, 19001920. Tesis doctoral de la Universitat de València. Web. 15 de noviembre de 2019. $<$ http://roderic.uv.es/handle/10550/30397>

Friedrich, Hugo. 2006. Die Struktur der modernen Lyrik. Von der Mitte des neunzehnten bis zur Mitte des zwanzigsten Jahrhunderts. Reinbek bei Hamburg, Rowohlt.

García Cristóbal, Javier. 2003. "Una aproximación a la influencia de Friedrich Nietzsche en la obra de Rubén Darío". Anales de Literatura Hispanoamericana 32: 103-14. Web. 15 de noviembre de 2019. <https://revistas.ucm.es/index.php/ALHI/article/view/ ALHI0303110103A>

Gutiérrez Girardot, Rafael. 1986. "El Modernismo incógnito". Aproximaciones. Bogotá: Procultura, 87-96.

Hüneburg, Erik Ewald. 2014. Nietzsche und die spanische Literatur der Moderne (18981936). Tesis doctoral de la Universität Würzburg. Web. 15 de noviembre de 2019. $<$ https://opus.bibliothek.uni-wuerzburg.de/frontdoor/index/index/year/2015/docId/11508>

Jauß, Hans Robert. 2013. La historia de la literatura como provocación. Traducido por Juan Godó Costa y José Luis Gil Aristu, Gredos. 
Moog-Grünewald, Maria. 1984. "Investigación de las influencias y la recepción”. Teoría y praxis de la literatura comparada. Ed. Manfred Schmeling. Traducido por Ignacio Torres Corredor. Barcelona: Alfa, 69-100.

Nietzsche, Friedrich. 1997. Asi hablaba Zaratustra: un libro para todos y para nadie. Traducido por Andrés Sánchez Pascual. Madrid: Alianza. . 2011. Correspondencia. Vol. 6: Octubre 1887 - Enero 1889. Edición de Luis Enrique de Santiago Guervós. Traducción, introducción, notas y apéndices de Joan B. Llinares. Madrid: Trotta.

. 2011. "Schopenhauer como educador". Obras completas. Vol. 1: Escritos de juventud. Edición de Andrés Sánchez Meca. Madrid: Tecnos, 749-806.

. 2010. Ecce homo: cómo se llega a ser lo que se es. Traducido por Andrés Sánchez Pascual. Madrid: Alianza. . 2008. Fragmentos póstumos. Vol. 4: 1885-1889. Edición de Diego Sánchez Meca, traducción, introducción y notas de Juan Luis Vermal y Joan B. Llinares, 2. ed. Madrid: Tecnos. 2004. El nacimiento de la tragedia o Grecia y el pesimismo. Traducido por Andrés Sánchez Pascual. Madrid: Alianza. . 2001. Crepúsculo de los ídolos o cómo se filosofa con el martillo. Traducido por Andrés Sánchez Pascual. Madrid: Alianza.

. 1999. Sämtliche Werke. Kritische Studienausgabe (KSA). 15 tomos. Edición de Giorgio Colli y Mazzino Montinari. München / Berlín / New York: Deutscher Taschenbuch Verlag / Walter de Gruyter.

. 1997. La genealogía de la moral: un escrito polémico. Traducido por Andrés Sánchez Pascual. Madrid: Alianza.

. 1990. La ciencia jovial: "La gaya scienza”. Traducido por José Jara. Caracas: Monte Ávila Editores.

Onís, Federico de. 1961. Antología de la poesía española e hispanoamericana (1882-1932). New York, Las Américas.

Oviedo, José Miguel. 1995. Historia de la literatura hispanoamericana. Vol. 2. Madrid: Alianza.

Reis, Carlos. 1979. Comentario de textos, metodología y diccionario de términos literarios. Trad. de Ángel Marcos de Dios. Salamanca: Almar.

Rivas Bravo, Noel. 1998. "Un raro excluido de Los raros". Rubén Dario: Estudios en el centenario de Los raros y Prosas profanas. Ed. Alfonso García Morales. Sevilla: Publicaciones de la Universidad de Sevilla, 69-84.

Rukser, Udo. 1962. Nietzsche in der Hispania. Ein Beitrag zur hispanischen Kultur- und Geistesgeschichte. Bern/München: Francke Verlag.

Schmigalle, Günther. 2018. "Darío, lector de Nietzsche”. Anales de Literatura Hispanoamericana 47: 125-140. Web. 15 de julio de 2020. <https://revistas.ucm.es/index.php/ ALHI/article/view/62731/4564456548911> .2016. "Yo soy el anticristo de la América Central». Lecturas y crisis espiritual de Rubén Darío en 1913”. Centroamericana 26.2: 159-177. Web. 15 de julio de 2020. <http:// 
www.centroamericana.it/wp-content/uploads/2017/05/CA-26.2-G\%C3\%BCntherSchmigalle-\%C2\%AB Yo-soy-el-anticristo-de-la-Am\%C3\%A9ricaCentral\%C2\%BB.-Lecturas-y-crisis-espiritual-de-Rub\%C3\%A9n-Dar\%C3\%ADo-en-1913.pdf>

Siebenmann, Gustav. 1982. "Modernismen und Avantgarde in der Iberoromania". Zur Geschichtlichkeit der Moderne. Der Begriff der literarischen Moderne in Theorie und Deutung. Ed. Theo Elm y Gerd Hemmerich. Múnich: Wilhelm Fink.

Sobejano, Gonzalo. 2004. Nietzsche en España (1890-1970). 2da. ed. corr. y ampl. Madrid: Gredos.

Tiniánov, Iuri. 2020. El problema de la lengua poética. Traducido por Eugenio López Arriazu. Buenos Aires: Dedalus.

Torres, Edelberto. 1982. La dramática vida de Rubén Dario. La Habana: Arte y Literatura.

Valera, Juan. 1917. "A D. Rubén Darío”. Azul... Por Rubén Darío. Vol. IV de Obras completas. Madrid: Mundo Latino, X-XxxI.

Ward, Thomas. diciembre de 2002. "Los posibles caminos de Nietzsche en el modernismo". Nueva Revista de Filología Hispánica, L.2: 489-515. Web. 15 de noviembre de 2019. <https://nrfh.colmex.mx/index.php/nrfh/article/view/2191>

Zima, Peter V. 2000. Theorie des Subjekts. Subjektivität und Identität zwischen Moderne und Postmoderne. Tübingen: Franke. 